some 172 habitats have been discerned in the terrestrial system as it is discussed in the book. This is done with practically no reference to the names of plants or geological phenomena!

A chapter is devoted to the methods used by the Survey to record the animals of Wytham Woods. The records were kept on the kind of punched card that has holes round the edge; these cards are selected by hand using needles. No doubt if the work at Wytham Woods were being started to-day an eighty-column IBM card or something similar would be used which would allow investigation of the accumulated data by computer. The Survey's card collection must contain a great amount of information that it is impracticable to attempt to retrieve by hand manipulation and which may also have escaped Dr. Elton's penetrating intuition.

Elton's writing shows a certain distrust of the approach to ecological problems that seeks to quantify data and to ascertain definable parameters of one kind or another. This is all very well, but it is quite impossible to devote the time and energy that has gone into the surveying of Wytham Woods to all our pressing ecological problems. To conserve or not to conserve can now be an urgent political question. Cases may range from the flooding of a valley to create a reservoir to a major change of land use in the tropics. At present such cases are examined in the light of the personal assessments of various individual biologists. Reliable techniques are urgently needed for rapid sampling, evaluation of data, and subsequent assessment of the relative values of various areas on a quantified basis.

One of the greatest values of this book is that it shows what excellent ecological work can be done on an observational footing in the kind of restricted area that is usually all that is easily accessible to university, school and other teaching departments of biology. The book is very readable and well illustrated. The author discusses the semanties of the word "pattern" and defends its use in his title; he does not give the same attention to such colloquialisms as "blue print" which one finds occur in his text! The use of these, and the numerous quotations from non-biological literature, will aid rather than discourage the reader and, like Dr. Elton's previous books, this book will be a source of information, encouragement and inspiration in any laboratory, from the school level upwards, where the ecology of animals is studied.

JoHN SMaRT

\section{UNFAIRLY ECLIPSED}

\section{Darwin's Moon}

A Biography of Alfred Russel Wallace. By A. WilliamsEllis. Pp. $x+261+5$. (London and Glasgow: Blackie and Son, Ltd., 1966.) 25s. net.

Alfred Russel Wallace, co-discoverer of the principle of natural selection and pioneer student of animal geography, has suffered from the lack of a definitive biography. His life has been treated with little sophisticated attention to the thought of his time, its influonce on him, or indeed the full significance of his own contributions to the corpus of Darwinian belief. The present work, while reflecting a sincere appreciation of Wallace's character, does not adequately fulfil the needs of the intellectual historian.

Darwin's Moon, as its title unfortunately suggests, tends to place Wallace in eclipse from the beginning. This situation arises not from intent but from an apparent lack of familiarity with collateral historical sources. For example, the author dismisses W. H. Edwards in a sentence, although this American traveller, through personal contact as well as by means of his book, strongly influenced Wallace and Bates in their selection of Amazonas as a collecting ground. Edwards did more than write a travelogue; he knew the "little worlds" of the great river. $\mathrm{He}$ made shrewd observations on variation under wild conditions-something which Wallace was later to emphasize to Darwin at a time when, in the first edition of the Origin, the latter was suffering from undue timidity on this score.

One is left with the impression that Edwards's Voyage Up the River Amazon was never consulted by Mrs. Williams-Ellis or, if so, that its content was not digested. At all events, it does not appear in her bibliography. Even from Wallace's Life we can learn that long years later, on his lecture trip to America, the naturalist sought out Edwards and renewed acquaintance with him-in fact, they corresponded as late as 1904 .

Similarly, Wallace's original interpretation of the role of the human brain in freeing man from particulate evolution goes unremarked in Darwin's Moon. Missing, too, is Wallace's two-stage theory of human evolution; that is, a first bipedal stage followed later by brain enlargement - a theory brilliantly confirmed in our time by the australopithecine discoveries. Again, "Wallace's Line" and its import, as analysed by later zoogeographers such as Ernst Mayr, are inadequately treated.

Such omissions do not serve the serious scientific historian. What remains is a pleasant, sympathetic account of Wallace's personal life-a life never totally free of financial anxiety. The book contributes little, however, that cannot be learned from Wallace's own autobiography, and it misses much that could have been gleaned from the letters published by James Marchant. Darwin's Moon may, nevertheless, help to preserve-if somewhat superficially-the memory of a great and unjustly neglected biologist.

LOREN EISELEx

\section{NUCLEAR CHEMISTRY}

\section{La Chimie Nucléaire}

Etude des Noyaux Radioactifs et des Réactions Nucléaires. Par Mare Lefort. Pp. xviii +509. (Paris: Dunod, 1966.) 68 francs.

UNLIKE several books that have appeared under substantially the first part of the title of this book, this is confined almost entirely to the subject of nuclear chemistry.

Professor M. Lefort deals with the investigation of nuclear reactions and radioactive changes by partially, or largely, chemical means, together with such nuclear physics as is essential to a proper theoretical basis for such studies. The treatment of this field is more detailed than in any other text-book with which I am acquainted. It is reminiscent of that adopted in the three famous articles in Reviews of Modern Physics that appeared in 1936,1937 and 1938.

The first three chapters cover the basic physics of radioactive decay processes, the properties of the radiations and the dynamics of nuclear reactions. The larger part of the book is devoted to nuclear reactions which are divided, in chapters, into those proceeding by way of a compound nucleus, spallation and reactions following the evaporation of one or more nucleons and reactions involving nucleon transfer and the Phillips-Oppenheimer process. Two long chapters are devoted to fission, the first covering asymmetric and low energy fission and the second symmetric and high energy fission. Together these provide a compact and up to date account of the fission process.

$\mathrm{Up}$ to this point the treatment emphasizes the fundamental features of the subject and is quantitative and simply mathematical in character, without ever demanding too much of the reader in the latter respect. The final two chapters of the book are very different. In one the author attempts to deal with the experimental techniques of the subject. At the beginning of the chapter he admits the impossibility of treating them all in detail comparable 